\title{
Ghrelin and leptin levels in obese adolescents. Relationship with body fat and insulin resistance
}

\author{
Charilaos Stylianou, ${ }^{1}$ Assimina Galli-Tsinopoulou, ${ }^{1}$ Dimitrios Farmakiotis, ${ }^{2}$ \\ Israel Rousso, ${ }^{3}$ Michael Karamouzis, ${ }^{4}$ George Koliakos, ${ }^{4}$ Sanda Nousia-Arvanitakis ${ }^{1}$
}

${ }^{1} 4^{\text {th }}$ Department of Pediatrics, ${ }^{2}$ Division of Endocrinology and Human Reproduction, $2^{\text {nd }}$ Department of Obstetrics and Gynecology, ${ }^{3}{ }^{\text {nd }}$ Department of Pediatrics, ${ }^{4}$ Department of Biochemistry, Medical School, Aristotle University of Thessaloniki, Greece

\begin{abstract}
OBJECTIVE: Ghrelin and leptin levels are influenced by body fat (BF\%), pubertal stage and possibly insulin resistance (IR). The aim of our study was: 1) To compare fasting ghrelin and leptin levels between obese and non-obese, adolescents, 2) to investigate possible correlations of these hormones with BF \%, as well as IR. DESIGN: Twenty obese insulin resistant (IR) adolescents, twenty obese non IR (NIR) and fifteen healthy non-obese, age-matched adolescents were studied. In all participants, height, weight, body mass index (BMI) and BF \% were measured. Fasting glucose, insulin, ghrelin and leptin levels were determined. IR was assessed using HOMA-IR index. RESULTS: BMI, BF \%, insulin and HOMA-IR values were positively correlated with leptin and negatively with ghrelin levels. A negative correlation between circulating leptin and ghrelin levels was found. A suggestive positive correlation between leptin levels and $\mathrm{BF} \%$, independent of $\mathrm{BMI}$, was also observed $(P=0.075)$. Ghrelin levels were significantly correlated with insulin levels and HOMA-IR, independent of BMI $(P=0.077)$. CONCLUSIONS: Obesity and IR may play an important role in the release of ghrelin as well as in the negative correlation between ghrelin and leptin.
\end{abstract}

Key words: Adolescents, Body fat, Ghrelin, Insulin resistance, Leptin, Obesity.

\section{INTRODUCTION}

Ghrelin and leptin are two hormones playing an important role in the regulation of food intake and

Address for correspondence:

Assimina Galli-Tsinopoulou, $4^{\text {th }}$ Department of Pediatrics, Aristotle University of Thessaloniki, Papageorgiou General Hospital, Ring Road Nea Efkarpia, GR - 56403 Thessaloniki, Greece, Tel: +30 2310 991537, Fax: +30 2310 991535, e-mail: galtsin@otenet.gr

Received 12-04-07, Revised 10-07-07, Accepted 10-08-07 body weight. ${ }^{1}$ Leptin is a 167 amino-residue peptide encoded by the obesity gene. ${ }^{2,3}$ It is secreted by fat tissue and suppresses food intake, while increasing energy expenditure. ${ }^{4}$ Following release into the circulation, leptin crosses the blood-brain barrier and binds to leptin receptors in the hypothalamus, influencing the activity of various hypothalamic neurons as well as the expression of various genes, encoding orexigenic and anorexigenic neuropeptides. ${ }^{5,6}$ Leptin levels are influenced by the amount of body fat, as they are found high in obese and low in lean individuals. ${ }^{7}$ 
Ghrelin is a 28 amino-residue peptide, produced predominantly by the stomach, and was initially discovered as an endogenous ligand for the growth hormone secretagogue receptor (GHS-R). ${ }^{8}$ Among several other biological functions, ghrelin was found to produce positive energy balance by promoting food intake ${ }^{9}$ and decreasing energy expenditure in rodents. ${ }^{10}$ It plays a role in the regulation of energy balance and attenuates leptin-induced reduction in food intake and body weight. Ghrelin also modulates the expression of orexigenic and anorexigenic neuropeptides. ${ }^{11,12}$ Ghrelin levels were found decreased in obese individuals, ${ }^{13}$ with the exception of patients with Prader-Willi syndrome,${ }^{14}$ and were found elevated in anorexia nervosa. ${ }^{15}$

Ghrelin and leptin levels are also influenced by the pubertal stage. Leptin concentrations vary with Tanner stage independent of adiposity. ${ }^{16}$ They are higher in females than males at Tanner stages IV and $\mathrm{V}$, but not at earlier stages of pubertal development. ${ }^{17}$ Ghrelin levels vary from fetal life through early adulthood. ${ }^{18}$ The highest levels of ghrelin are found during early postnatal life, when growth hormone begins to exert its effects on growth and important changes in food intake occur, suggesting that this hormone may participate in these processes. ${ }^{18}$ Prepubertal children have higher ghrelin concentrations than those in puberty. ${ }^{19}$

Based on the above data, the present study was designed: 1) to compare fasting ghrelin and leptin levels between obese and non-obese adolescents, and 2) to investigate any correlation between these two hormones and body fat (BF \%) as well as insulin resistance (IR).

\section{PATIENTS AND METHODS}

\section{Patients}

Twenty obese, insulin resistant (IR) adolescents (13 females, 7 males), aged (mean \pm SE) $12.86 \pm 1.82$ years and twenty obese non insulin resistant (NIR) adolescents ( 10 females, 10 males), aged $12.72 \pm 1.87$ years, with a mean body mass index (BMI) of $30.74 \pm 4.53$ and $29.43 \pm 3.87$, respectively $\left(>97^{\text {th }}\right.$ percentile for age and sex) ${ }^{20}$ were included in the study. Insulin resistance (IR) was defined by the Homeostasis Model for the Assessment of Insulin Resistance (HOMA-IR) ${ }^{21}$ as a value $>3.16($ mean \pm SE: $4.54 \pm 1.32) .{ }^{22}$

Fifteen healthy non obese adolescents, matched for age, ( 9 females and 6 males, mean age $12.81 \pm 1.11$ years), served as the control group (Table 1).

All the participants were screened by medical history and physical examination. None of them had any chronic disease or was undergoing any pharmacological treatment. By applying the five-stage system described by Tanner and Marshall to assess normal pubertal development, ${ }^{23,24}$ all were found to be pubertal. Body weight and height were measured in duplicate using a SEGA weighing-scale (SEGA 711) and stadiometer (HARPENDEN). Body mass index

Table 1. Anthropometric, hormonal and metabolic features of the adolescents studied: mean \pm SD, (range). $x^{2}$ or Kruskal-Wallis $P$ values.

\begin{tabular}{|c|c|c|c|c|c|c|c|}
\hline & \multicolumn{4}{|c|}{ OBESE ADOLESCENTS } & \multirow{2}{*}{\multicolumn{2}{|c|}{ CONTROLS $(n=15)$}} & \multirow[t]{2}{*}{$\mathbf{P}$} \\
\hline & \multicolumn{2}{|c|}{ IR $(n=20)$} & \multicolumn{2}{|c|}{ NIR $(n=20)$} & & & \\
\hline Gender (M/F) & \multicolumn{2}{|c|}{$7 / 13$} & \multicolumn{2}{|c|}{$10 / 10$} & \multicolumn{2}{|c|}{$9 / 6$} & $=0.185$ \\
\hline Age (years) & $12.86 \pm 1.82$ & $(10.58-15.83)$ & $12.72 \pm 1.87$ & $(10.83-16.00)$ & $12.81 \pm 1.11$ & $(11.33-15.08)$ & $=0.163$ \\
\hline $\operatorname{BMI}\left(\mathrm{kg} / \mathrm{m}^{2}\right)$ & $30.54 \pm 4.73^{\dagger}$ & $(23.63-46.00)$ & $29.43 \pm 3.87^{\dagger}$ & $(21.57-34.52)$ & $19.97 \pm 3.14^{*}$ & $(15.90-25.80)$ & $<0.001$ \\
\hline $\mathrm{BF} \%$ & $35.58 \pm 6.00^{\dagger}$ & $(25.20-47.90)$ & $34.33 \pm 5.14^{\dagger}$ & $(25.10-42.50)$ & $21.10 \pm 7.31^{*}$ & $(9.80-32.70)$ & $<0.001$ \\
\hline Glucose (mg/dl) & $4.76 \pm 0.54$ & $(4.03-5.70)$ & $4.77 \pm 0.59$ & $(3.38-5.90)$ & $4.86 \pm 5.72$ & $(3.93-5.58)$ & $=0.867$ \\
\hline Insulin $(\mu \mathrm{IU} / \mathrm{ml})$ & $143.78 \pm 41.32^{\dagger *}$ & $(89.68-246.82)$ & $64.64 \pm 19.01$ & $(23.46-97.58)$ & $59.98 \pm 18.72$ & $(30.06-92.55)$ & $<0.001$ \\
\hline HOMA-IR & $4.54 \pm 1.32^{\dagger *}$ & $(3.16-8.49)$ & $1.80 \pm 0.55$ & $(0.72-2.82)$ & $1.79 \pm 0.54$ & $(0.98-2.90)$ & $<0.001$ \\
\hline Leptin (ng/ml) & $46.33 \pm 28.02^{\dagger}$ & $(10.70-121.10)$ & $34.74 \pm 17.93^{\dagger}$ & $(13.71-86.30)$ & $11.64 \pm 6.57^{*}$ & $(2.10-24.29)$ & $<0.001$ \\
\hline Ghrelin (pmol/l) & $860.12 \pm 289.89^{\dagger *}$ & (376.77-1619.36) & $102.09 \pm 366.10$ & 735.47-1955.76) & $1358.47 \pm 401.15^{*}$ & (1011.87-2665.12) & $<0.001$ \\
\hline
\end{tabular}

IR: insulin-resistant, NIR: non insulin-resistant; ${ }^{\dagger} \mathrm{P}<0.05$ vs. controls. ${ }^{*} \mathrm{P}<0.05$ vs. NIR obese adolescents. 
(BMI) was calculated (weight in kilograms divided by the square of height in meters). Bioelectrical Impedance Analysis (BIA) (MALTRON analyzer BF-906) was applied to estimate body fat \% (BF \%), according to the manufacturer's and NIH instructions. ${ }^{25}$

\section{Study protocol}

After an overnight fast, morning blood samples were drawn from all subjects included in the study. Blood samples were centrifuged (10 min at $1500 \mathrm{~g}$ ) and the aliquots were stored at $-20^{\circ} \mathrm{C}$ until assayed according to the instructions published by Groeschl et al regarding ghrelin. ${ }^{26}$

In all groups, fasting glucose, ghrelin, leptin and insulin levels were measured. The obese adolescents underwent a standard oral glucose tolerance test (OGTT) $-1.75 \mathrm{~g} / \mathrm{kg}$ body weight (max. $75 \mathrm{~g}$ ) of glucose per os - in order to exclude any participants having impaired glucose test (IGT) and to enable the use of fasting index HOMA-IR to define IR. ${ }^{27}$

The study was approved by the Scientific Ethics Committee of the Medical School of the Aristotle University of Thessaloniki. Informed written consent was obtained from the parents of all adolescents who underwent clinical and biochemical investigation.

\section{Assays and calculations}

\section{Glucose}

Serum glucose was determined with the glucose hexokinase enzymatic method (Architect c8000, Abbott Laboratories, Il, USA).

\section{Insulin}

Serum insulin was determined applying a solidphase, two-site immunometric assay (Immulite 2000; DPC, USA), which had a coefficient of variation (CV) of $4.1-7.3 \%$ and a sensitivity of $2 \mu \mathrm{IU} / \mathrm{ml}$.

\section{Leptin}

Serum leptin was determined by a commercial radioimmunoassay (DSL-23100 Active Human Leptin IRMA; DSL, USA). The lower limits of detection for leptin were $0.10 \mathrm{ng} / \mathrm{ml}$, while inter-assay and intraassay CV were 7.6 and 5\%, respectively.

\section{Ghrelin}

Serum ghrelin was measured by radioimmunoassay (Phoenix Pharmaceuticals Inc., Belmont, CA, USA).
This assay uses a ${ }^{125}$-labeled ghrelin tracer and a rabbit polyclonal antibody against full-length, octanoylated human ghrelin that recognizes the acylated and desacyl forms. The antiserum does not cross-react with any relevant peptide, according to the information provided by the manufacturer. The lower and upper detection limits were 80 and $2500 \mathrm{pg} / \mathrm{ml}$. The intraand the inter-assay coefficients of variation (CV) were $5.30 \%$ and $13.61 \%$, respectively.

\section{Insulin resistance}

Insulin resistance (IR) was assessed using the Homeostasis model assessment (HOMA-IR) according to the formula: fasting insulin $(\mu \mathrm{IU} / \mathrm{ml}) \mathrm{x}$ fasting glucose $(\mathrm{mmol} / \mathrm{l}) / 22.5 .^{21}$

\section{Statistical analysis}

All analyses were performed by the statistical package SPSS, v.13.0 (SPSS Inc., Chicago, IL, USA). Two-tailed significance was set at $5 \%$. The $\mathrm{x}^{2}$ criterion was used to test for significant differences in gender distribution between the three groups. Given the relatively small number of cases per group, means were subsequently compared with the non-parametric Kruskal-Wallis test; pairwise comparisons were performed with the Mann-Whitney U-test, in cases of $\mathrm{K}-\mathrm{W} \mathrm{P}<0.05$. Bivariate correlations were assessed with the Spearman coefficient. Independent correlations were evaluated by means of stepwise multiple regression and partial correlation analysis.

\section{RESULTS}

The anthropometric, hormonal and metabolic features of all adolescents studied are presented in Table 1 . No statistically significant difference in age or gender distribution was observed between the three groups. No significant difference in ghrelin or leptin levels was observed between males and females in the two groups of obese adolescents $(\mathrm{P}=0.166$ and 0.630 , respectively). In the control group, females had significantly higher leptin levels $(16.37 \pm 5.86)$ compared to males $(8.43 \pm 5.07, \mathrm{P}=0.022)$ (Table 2).

Obese adolescents (both IR and NIR) had significantly higher $\mathrm{BMI}$ and $\mathrm{BF} \%$ values compared to controls $(\mathrm{P}<0.001$ in all comparisons); no significant differences in $\mathrm{BMI}$ or $\mathrm{BF} \%$ was observed between the two groups (IR and NIR) of obese adolescents 
Table 2. Ghrelin and leptin levels in male (M) and female (F) adolescents studied separately (mean \pm SD, range, Mann-Whitney P values).

\begin{tabular}{|c|c|c|c|c|c|c|c|c|c|}
\hline \multirow[b]{2}{*}{ Gender } & \multicolumn{3}{|c|}{ Obese Adolescents IR } & \multicolumn{3}{|c|}{ Obese Adolescents NIR } & \multicolumn{3}{|c|}{ Controls } \\
\hline & $\mathbf{M}$ & $\mathbf{F}$ & $\mathbf{P}$ & $\mathbf{M}$ & $\mathbf{F}$ & $\mathbf{P}$ & M & $\mathbf{F}$ & $\mathbf{P}$ \\
\hline $\mathrm{n}$ & 6 & 14 & & 10 & 10 & & 10 & 5 & \\
\hline $\begin{array}{l}\text { Leptin } \\
(\mathrm{ng} / \mathrm{ml})\end{array}$ & $\begin{array}{c}44.18 \pm 20.06 \\
17.12-66.63\end{array}$ & $\begin{array}{l}47.26 \pm 31.46 \\
10.70-121.10\end{array}$ & $=0.444$ & $\begin{array}{c}35.97 \pm 20.33 \\
16.39-86.30\end{array}$ & $\begin{array}{c}33.52 \pm 16.19 \\
13.71-68.62\end{array}$ & $=0.971$ & $\begin{array}{l}8.43 \pm 5.06 \\
2.10-16.06\end{array}$ & $\begin{array}{c}16.37 \pm 5.86 \\
6.52-24.29\end{array}$ & $=0.022$ \\
\hline $\begin{array}{l}\text { Ghrelin } \\
(\mathrm{pmol} / \mathrm{l})\end{array}$ & $\begin{array}{l}903.44 \pm 290.28 \\
419.93-1285.20\end{array}$ & $\begin{array}{l}841.55 \pm 298.63 \\
376.77-1619.36\end{array}$ & $=0.968$ & $\begin{array}{c}960.74 \pm 235.63 \\
756.82-1580.07\end{array}$ & $\begin{array}{c}1243.44 \pm 427.83 \\
735.47-1955.76\end{array}$ & $=0.089$ & $\begin{array}{l}1317.49 \pm 195.1 \\
1032.71-1618.5\end{array}$ & $\begin{array}{l}1419.94 \pm 618.52 \\
1011.87-2665.12\end{array}$ & $=0.529$ \\
\hline
\end{tabular}

IR: insulin-resistant, NIR: non-insulin-resistant, $\mathrm{P}$ values $<0.05$ are significant.

(Table 1). Obese IR adolescents had significantly higher insulin levels, as well as HOMA-IR values, compared to obese NIR adolescents and controls $(\mathrm{P}<0.001$ in all comparisons); no significant difference in the indices of IR was observed between obese NIR adolescents and controls.

Fasting glucose levels did not significantly differ between the three groups (Table 1).

Leptin levels were significantly higher in obese (IR and NIR) adolescents compared to controls $(\mathrm{P}<0.001$ in both comparisons). Obese IR adolescents had higher leptin levels compared to obese NIR individuals, but not significantly so (Table 1, Figure 1).

Ghrelin levels were significantly lower in obese IR and NIR adolescents compared to the control group ( $\mathrm{P}<0.001$ and $\mathrm{P}=0.006$, respectively). Ghrelin levels were significantly lower in IR compared to NIR obese adolescents $(\mathrm{P}=0.043)$ (Table 1, Figure 2).

Bivariate and independent of (partial for) BMI correlations are summarized in Table 3. Leptin concentrations were positively correlated with indices of obesity (BMI and BF \%) and IR (insulin levels and HoMA-IR) $(\mathrm{P}<0.001$ in all comparisons) (Table 3 ). Serum ghrelin levels were negatively correlated with both obesity and IR $(\mathrm{P}<0.001$ in all comparisons) (Table 3, Figure 3). A significant negative correlation between circulating leptin and ghrelin was found $(\mathrm{P}<0.001)$ (Table 3, Figure 4).

After adjustment for BMI, circulating leptin levels were positively correlated with fasting insulin levels and HOMA-IR values, but these correlations were suggestive $(\mathrm{P}=0.075$ and $\mathrm{P}=0.077$, respectively) (Table
3). Notably, a suggestive positive correlation between leptin concentrations and $\mathrm{BF} \%$, independent of $\mathrm{BMI}$, was also observed $(\mathrm{P}=0.072)$ (Table 3$)$.

Ghrelin levels were significantly negatively correlated with fasting insulin levels and HOMA-IR values $(\mathrm{P}=0.022)$ (Table 3 , Figure 3$)$, independent of BMI (Table 3).

In multiple regression analysis, leptin levels were independently associated only with BMI values $\left(\mathrm{B}=2.55 \pm 4.32, \mathrm{R}^{2}=3.98 ; \mathrm{P}<0.001\right)$. By contrast, one

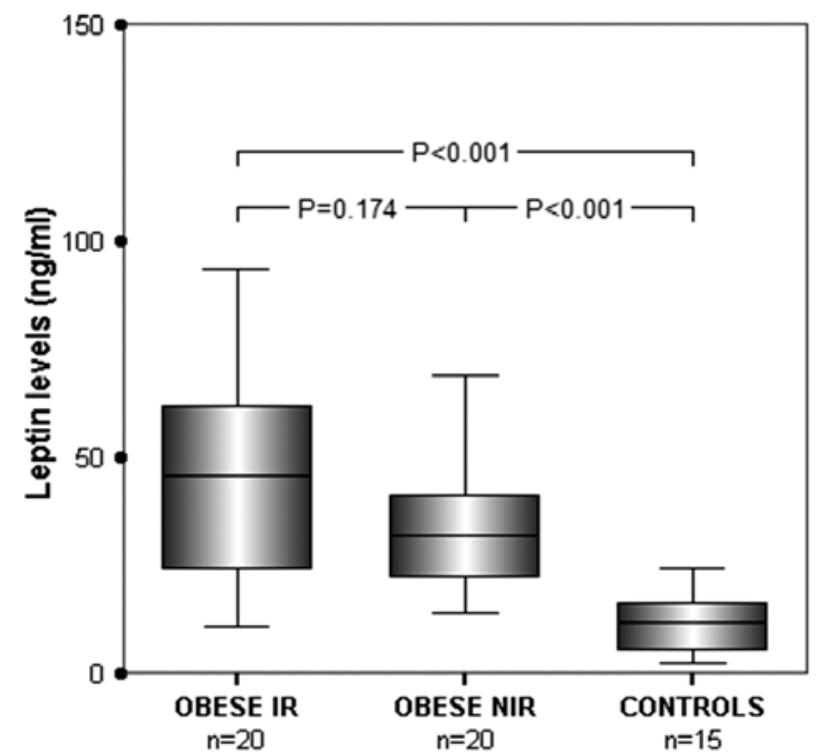

Figure 1. Serum leptin levels in obese insulin-resistant (OBESE IR) adolescents, obese non-insulin-resistant (OBESE NIR) adolescents and lean adolescents (CONTROLS). Box-plots extend from the $25^{\text {th }}$ to the $75^{\text {th }}$ percentile and whiskers to the largest and smallest observed values within 1.5 box lengths; the solid line is the median. 


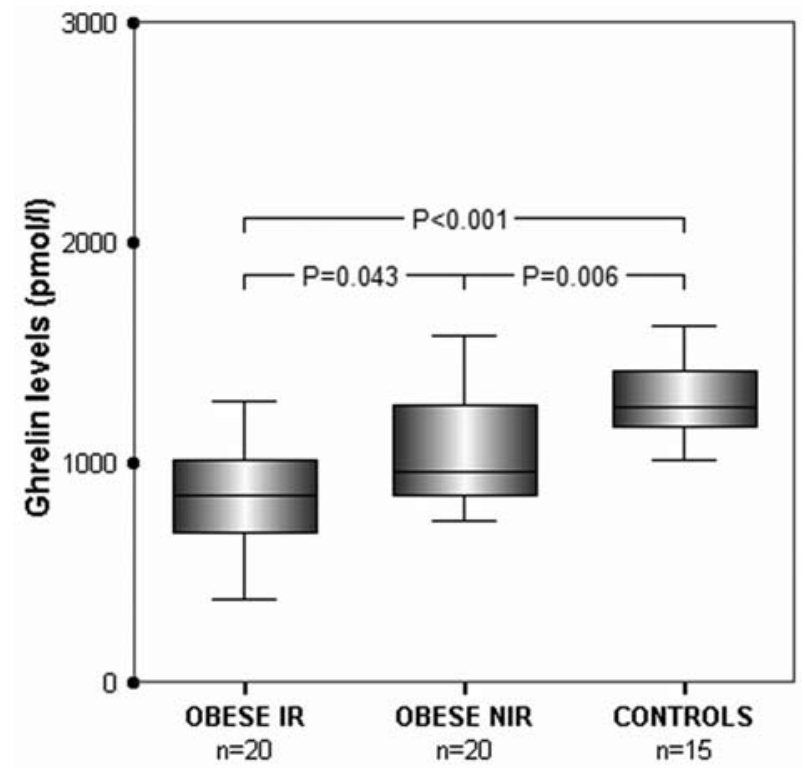

Figure 2. Serum ghrelin levels in obese insulin-resistant (OBESE IR) adolescents, obese non-insulin-resistant (OBESE NIR) adolescents and lean adolescents (CONTROLS). Box-plots as in Figure 1.

acceptable model $\left(\mathrm{R}^{2}=2.43\right)$ for ghrelin concentrations included both $\mathrm{BMI}(\mathrm{B}=-19.32 \pm 9.14, \mathrm{P}=0.039)$ and fasting insulin $(\mathrm{B}=-16.4 \pm 8.13, \mathrm{P}=0.049)$ levels.

\section{DISCUSSION}

In our study, ghrelin levels were found to be significantly lower in IR obese adolescents compared to NIR obese and to non obese adolescents. These findings are in agreement with those of other studies conducted in adults ${ }^{28}$ and children, ${ }^{29}$ indicating that IR may play an important role in the release of ghrelin and probably in the interaction between ghrelin and leptin. In the present study, this relationship was substantiated by the significant negative correlation of markers of IR with ghrelin levels, independent of obesity (Table 3, Figures 2 and 3).

Regarding the exact relationship between ghrelin and insulin, conflicting results have been reported. In a study conducted by Adeghate et al, ghrelin was found to stimulate insulin secretion from the pancreas of normal and diabetic rats, ${ }^{30}$ whereas Egido et al reported an inhibitory effect of ghrelin on insulin and somatostatin secretion. ${ }^{31}$ Schaller et al, on the other hand, reported that plasma ghrelin concentrations are not regulated by glucose or insulin. ${ }^{32}$ According to this study, hyperinsulinemia at concentrations typically seen in IR did not affect plasma ghrelin levels. In the same study, it was observed that insulin at pharmacological concentrations caused a dose-dependent decrease in circulating plasma ghrelin. Glucose in combination with supraphysiological insulin concentrations might cross the blood-brain barrier more easily and influence the central regulation of gastric ghrelin release. Saad et al reported that insulinemia possibly mediates the effect of nutritional status and energy balance on plasma ghrelin. ${ }^{33}$ Notably, insulin could play a pivotal role in regulating body weight through its down-regulating effects on plasma ghrelin concentrations. Finally, Erdman et al have reached the conclusion that in obese subjects with associated hyperinsulinemia, ghrelin suppression is due to insulin, whereas leptin can be important for reduction of ghrelin release during moderate increases of body weight. ${ }^{34}$

The BMI-independent relationship between leptin

Table 3. Bivariate and independent (partial), controlling for BMI, correlations of serum leptin and ghrelin levels to parameters of obesity and insulin resistance in 11 adolescents studied.

\begin{tabular}{|c|c|c|c|c|c|c|c|c|}
\hline & \multicolumn{4}{|c|}{ LEPTIN } & \multicolumn{4}{|c|}{ GHRELIN } \\
\hline & \multicolumn{2}{|c|}{ Bivariate } & \multicolumn{2}{|c|}{ Partial for BMI } & \multicolumn{2}{|c|}{ Bivariate } & \multicolumn{2}{|c|}{ Partial for BMI } \\
\hline & $\mathbf{r}_{\text {Spearm }}$ & $\mathbf{P}$ & $\mathbf{r}_{\mathrm{p} \mathrm{corr}}$ & $\mathbf{P}$ & $\mathbf{r}_{\text {Spearm }}$ & $\mathbf{P}$ & $\mathbf{r}_{\mathrm{p} \mathrm{corr}}$ & $\mathbf{P}$ \\
\hline BMI & +0.735 & $<0.001$ & --------- & --------- & -0.490 & $<0.001$ & --------- & -------- \\
\hline $\mathrm{BF} \%$ & +0.617 & $<0.001$ & +0.247 & $=0.072$ & -0.445 & $<0.001$ & +0.009 & $=0.948$ \\
\hline Insulin & +0.497 & $<0.001$ & +0.244 & $=0.075$ & -0.497 & $<0.001$ & -0.311 & $=0.022$ \\
\hline HOMA-IR & +0.502 & $<0.001$ & +0.242 & $=0.077$ & -0.454 & $<0.001$ & -0.312 & $=0.022$ \\
\hline Leptin & --------- & --------- & --------- & --------- & -0.466 & $<0.001$ & -0.111 & $=0.425$ \\
\hline Ghrelin & -0.466 & $<0.001$ & -0.111 & $=0.425$ & --------- & --------- & -------- & --------- \\
\hline
\end{tabular}




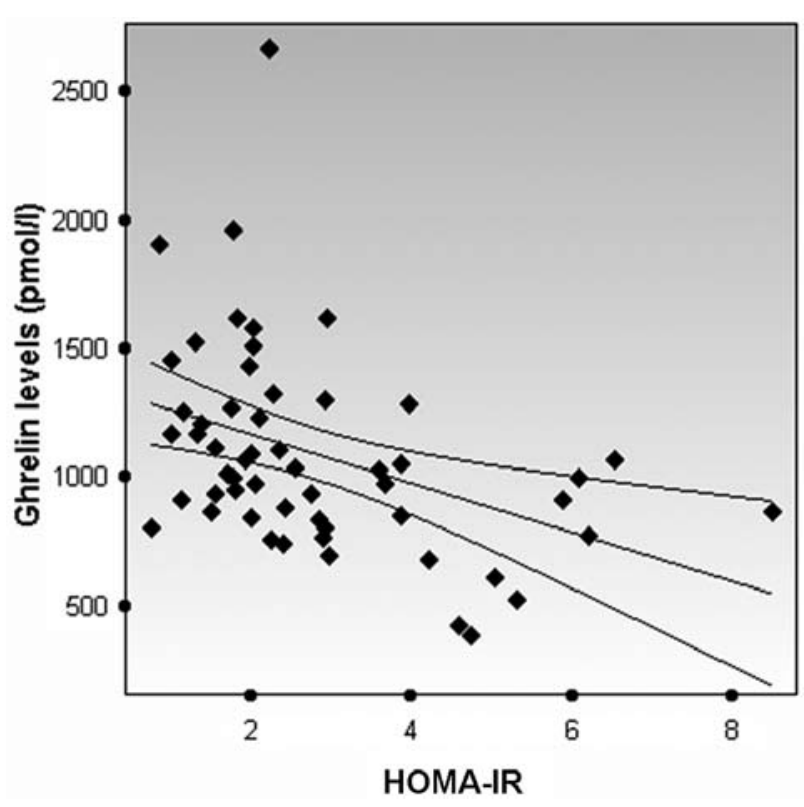

Figure 3. Scatter-plot diagram of serum ghrelin levels vs. HOMA-IR values in all adolescents studied (regression line \pm $95 \%$ C.I.).

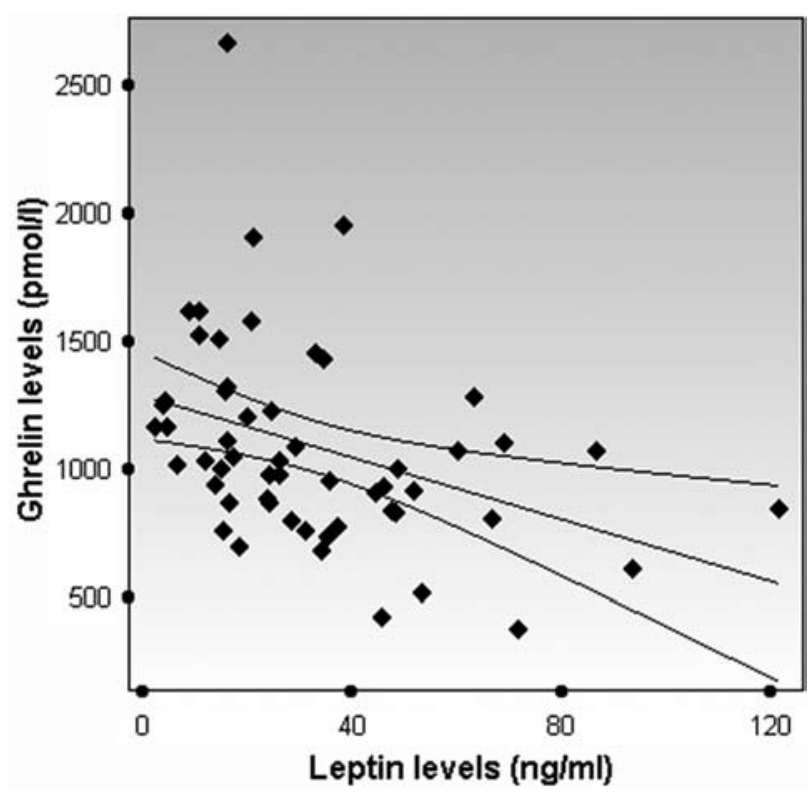

Figure 4. Scatter-plot diagram of serum ghrelin vs. leptin levels in all adolescents studied (regression line $\pm 95 \%$ C.I.).

and IR was less marked; nevertheless, based on the present findings one cannot exclude the possibility that, in adolescents, leptin might also be positively correlated with IR, independent of obesity, since differences of borderline statistical significance were detected (Tables 1 and 3, Figure 1).

In the literature it is well documented that leptin has gender differences. Although prepubertally leptin levels do not differ between boys and girls, with the onset of puberty leptin levels increase in girls and decrease in boys. ${ }^{35}$ This could be explained by the fact that girls gain more fat mass than boys, whereas boys gain more fat-free mass. This marked sexual dimorphism that is present in serum leptin levels at puberty, especially when weight ${ }^{36}$ is considered, result from genotype by sex interactions mediated by testosterone. ${ }^{37}$ Genes which influence variation in leptin levels are differentially expressed depending on sex and, moreover, sexes show differences in response to the expression of this obesity-related trait to unmeasured residual effects. ${ }^{37}$ This sexual dimorphism of leptin was confirmed in our study only in the group of normal-weight individuals (control group), in which females had significantly higher leptin levels compared to males. This is in agreement with the study conducted by Nakanishi et $\mathrm{al}^{36}$ in which sexual dimorphism in leptin levels and relative weight was found in normal-weight but not in overweight children and adolescents.

There are conflicting data with regard to gender differences in ghrelin levels. In certain studies, ghrelin levels were found comparable in men and women, ${ }^{38,39}$ while in others ${ }^{40-42}$ the observed differences in ghrelin levels according to gender refer only to healthy individuals. Thus in the study conducted by Makovey et al, ${ }^{40}$ in the obese group no significant gender differences were found. In our study, the absence of statistical significance in ghrelin levels between male and female adolescents could be attributed to the relatively small number of individuals involved.

It is known that ghrelin and leptin are two secreted peptides which apparently play an important role in the regulation of food intake and body weight ${ }^{1}$. Leptin, acts on regulatory centres in the brain to inhibit food intake and increase energy expenditure, thus acting as a long-term regulator of body weight. ${ }^{4}$ Ghrelin, on the other hand, is a fast-acting hormone that operates as a meal-initiation signal ${ }^{9}$ in the system for short-term regulation of energy balance. Therefore, it is possible that a negative interplay between the two hormones exists, as demonstrated in the present 
study (Figure 4).

In rodents, leptin has been shown to be an upstream regulator of ghrelin, ${ }^{43,44}$ whereas in humans, several studies have produced conflicting results. Tschöp et al demonstrated that, in obese individuals, fasting leptin levels are negatively correlated with fasting ghrelin concentrations.$^{45}$ However, in a study conducted by Ikezaki et al in obese children and adolescents, fasting leptin and ghrelin levels were not significantly correlated.$^{46}$ As mentioned above, the results of the present study support the notion that leptin and ghrelin levels are negatively correlated (Figure 4).

Regarding the negative association between ghrelin and leptin that was found in our study, this could simply reflect BMI associations. An inverse relationship between leptin and ghrelin has been reported in several studies ${ }^{47,48}$ which would support a contribution of leptin to obesity-related low ghrelin levels. However, the experimental evidence for such a negative feedback control is still a matter of debate. In mice, leptin administered intraperitoneally inhibits ghrelin release, ${ }^{49}$ while in rats leptin can prevent the rise of ghrelin during food restriction. ${ }^{50}$ In contrast to these findings in rodents, Chan et al reported that administration of recombinant leptin in lean individuals had no effect on plasma ghrelin concentrations. ${ }^{51}$ It is speculated that through the hypothalamic/pituitary axis ghrelin and leptin operate as a metabolic switch. ${ }^{52}$

Ghrelin suppression may be another feature of IR in obese adolescents. ${ }^{29}$ It should be noted that the estimation of IR by means of fasting indices, instead of the golden standard (i.e. the hyperisulinemic euglycemic clamp), poses some limitations in the interpretation of our results..$^{53}$ Other limitations include the relatively small number of subjects and the use of BIA for the estimation of BF \%.

In conclusion, the findings of the present study support the thesis that ghrelin is negatively correlated with leptin, obesity and insulin resistance. In adolescents, ghrelin is negatively correlated with IR, independent of obesity. The exact relationship between leptin, ghrelin, body fat and insulin resistance needs to be further clarified by both in vitro experiments and larger-scale studies.

\section{REFERENCES}

1. Klork M D, Jakobsdottir S, Drent M L, 2007 The role of leptin and ghrelin in the regulation of food intake and body weight in humans: a review. Obesity Reviews 8: 21-34.

2. Bray GA, York DA, 1997 Leptin and Clinical Medicine: A New Piece in the Puzzle of Obesity. J Clin Endocrinol Metab 82: 2771-2776.

3. Zhang Y, Proenca R, Maffei M, Barone M, Leopold L, Friedman JM, 1994 Positional cloning of the mouse obese gene and its human homologue. Nature 372: 425-432.

4. Rohner-Jeanrenaud F, Jeanrenaud B, 1996 Obesity, Leptin and the Brain. N Eng J Med 334: 324-325.

5. Sahu A, 2004 Leptin signalling in the hypothalamus: emphasis on energy homeostasis and leptin resistance. Front Neuroendocrinol 24: 225-253.

6. Sahu A, 1998 Evidence suggesting that galanin (GAL), melanin-concentrating hormone $(\mathrm{MCH})$, neurotensin (NT), proopiomelanocortin (POMC) and neuropeptide Y (NPY) are targets of leptin signalling in the hypothalamus. Endocrinology 139: 795-798.

7. Monteleone P, Fabrazzo M, Tortorella A, Fuschino A, Maj M, 2002 Opposite modifications in circulating leptin and soluble leptin receptor across the eating disorder spectrum. Mol Psych 7: 641-646.

8. Kojima M, Hosoda H, Date Y, Nakazato M, Matsuo H, Kangawa K, 1999 Ghrelin is a growth hormone-releasing acylated peptide from stomach. Nature 402: 656-660.

9. Wren AM, Seal LJ, Cohen MA, et al, 2001 Ghrelin enhances appetite and increases food intake in humans. $\mathrm{J}$ Clin Endocrinol Metab 86: 5992

10. Tschöp M, Smiley DL, Heiman ML, 2000 Ghrelin induces adiposity in rodents. Nature 407: 908-913.

11. Kamegai J, Tamura H, Shimizu T, Ishii S, Sugihara H, Wakabayashi I, 2001 Chronic central infusion of ghrelin increases hypothalamic neuropeptide Y and Agoutirelated protein mRNA levels and body weight in rats. Diabetes 50: 2438-2443.

12. Toshinai K, Date Y, Murakami N, et al, 2003 Ghrelininduced food intake is mediated via the orexin pathway. Endocrinology 144: 1506-1512.

13. Tschöp M, Weyer C, Tataranni PA, et al, 2001 Circulating Ghrelin levels are decreased in human obesity. Diabetes 50: 707-709.

14. Haqq AM, Farooqi IS, O'Rahilly S, et al, 2003 Serum ghrelin levels are inversely correlated with body mass index, age, and insulin concentrations in normal children and are markedly increased in Prader-Willi syndrome. J Clin Endocrinol Metab 88: 174-178.

15. Otto B, Cuntz U, Fruehauf E, Wawarta R, Folwaczny C, Riepl RL, 2001 Weight gain decreases elevated plasma Ghrelin concentrations of patients with anorexia nervosa. Eur J Endocrinol 145: 669-673.

16. Hassink SG, Sheslow DV, de Lancey E, Opentanova I, Considine RV, Caro JF, 1996 Serum leptin in children 
with obesity: relationship to gender and development. Pediatrics 98: 201-203.

17. Horlick MB, Rosenbaum M, Nicolson M, et al, 2000 Effect of puberty on the relationship between circulating leptin and body composition. J Clin Endocrinol Metab 85: 2509-2518.

18. Soriano-Guillen L, Barrios V, Chowen JA, et al, 2004 Ghrelin levels from fetal life through early adulthood: relationship with endocrine and metabolic and anthropometric measures. J Pediatr 144: 30-35.

19. Whatmore AJ, Hall CM, Jones J, Westwood M, Clayton PE, 2003 Ghrelin concentrations in healthy children and adolescents. Clin Endocrinol 59: 649-654.

20. Cole TJ, Bellizi MC, Flegal KM, Dietz WH, 2000 Establishing a standard definition for child overweight and obesity worldwide: international survey. BMJ 320: 1240-1243.

21. Matthews DR, Hosker JP, Rudenski AS, Naylor BA, Treacher DF, Turner RC, 1985 Homeostasis model assessment: insulin resistance and $\beta$-cell function from fasting plasma glucose and insulin concentrations in man. Diabetologia 28: 412-419.

22. Keskin M, Kurtoglou S, Kenderci M, Atabek M, Yazici C, 2005 Homeostasis Model Assessment is more reliable than Fasting Glucose to Insulin Ratio and Quantitative Insulin Sensitivity Check Index for assessing insulin resistance among obese children and adolescents. Paediatrics 115: 500-503.

23. Marshall WA, Tanner JM, 1969 Variations in pattern of pubertal changes in girls. Arch Dis Child 44: 291-303.

24. Marshall WA, Tanner JM, 1970 Variations in pattern of pubertal changes in boys. Arch Dis Child 45: 13-23.

25. Bioelectrical impedance analysis in Body composition Measurement, 1994 NIH Technol Assess Statement Online 12-14.

26. Groeschl M, Wagner R, Doetsch J, Rascher W, Rauh M, 2002 Preanalytical influences on the measurement of ghrelin. Clin Chem 48: 1114-1116.

27. Gungor N, Saad R, Janosky J, Arslanian S, 2004 Validation of surrogate estimates of insulin sensitivity and insulin secretion in children and adolescents. J Pediatr 144: 47-55.

28. McLaughlin T, Abbasi F, Lamendola C, Frayo RS, Cummings D, 2004 Plasma Ghrelin concentrations are decreased in insulin-resistant obese adults relative to equally obese insulin-sensitive controls. J Clin Endocrinol Metab 89: 1630-1635.

29. Bacha F, Arslanian SA, 2005 Ghrelin suppression in overweight children: a manifestation of insulin resistance? J Clin Endocrinol Metab 90: 2725-2730.

30. Adeghate E, Ponery AS, 2002 Ghrelin stimulates insulin secretion from the pancreas of normal and diabetic rats. J Neuroendocrinol 14: 555-560.

31. Egito EM, Rondriguez-Gallardo J, Silvestre RA, Marco J, 2002 Inhibitory effect of ghrelin on insulin and pancreatic somatostatin secretion. Eur J Endocrinol 146: 241-244.
32. Schaller G, Schmidt A, Pleiner J, Woloszczuk W, Wolzt M, Luger A, 2003 Plasma ghrelin concentrations are not regulated by glucose or insulin: a double -blind, placebo -controlled crossover clamp study. Diabetes 52: 16-20.

33. Saad M, Bernaba B, Hwu C, et al, 2002 Insulin regulates plasma ghrelin concentration. J Clin Endocrinol Metab 87: 3997-4000.

34. Erdmann J, Lippl F, Wagenpfeil S, Schusdziarra V, 2005 Differential association of basal and postprandial plasma ghrelin with leptin, insulin and type 2 diabetes. Diabetes 54: 1371-1378.

35. Ahmed ML, Ong KK, Morrell DJ, et al, 1999 Longitudinal study of leptin concentrations during puberty: sex differences and relationship to changes in body composition. J Clin Endocrinol Metab 84: 899-905.

36. Nakanishi T, Li R, Liu Z, Yi M, Nakagawa Y, Ohzeki T, 2001 Sexual dimorphism in relationship of serum leptin and relative weight for the standard in normal-weight, but not in overweight, children as well as adolescents. Eur J Clin Nutr 55: 989-993.

37. Martin LJ, Mahaney MC, Almasy L, et al, 2002 Leptin's sexual dimorphism results from genotype by sex interactions mediated by testosterone. Obes Res 10: 14-21.

38. Bellone S, Rapa A, Vivenza D, et al, 2002 Circulating ghrelin levels as function of gender, pubertal status and adiposity in childhood. J Endocrinol Invest 25: 13-15.

39. Purnell J, Weigle D, Breen P, Cummings D, 2003 Ghrelin levels correlate with insulin levels, insulin resistance and high-density lipoprotein cholesterol, but not with gender, menopausal status, or cortisol levels in humans. J Clin Endocrinol Metab 88: 5747-5752.

40. Makovey J, Naganathan V, Seibel M, Sambrook P, 2007 Gender differences in plasma ghrelin and its relations to body composition and bone- an opposite-sex twin study. Clin Endocrinol 66: 530-537.

41. Schuessler P, Uhr M, Ising M, Schmid D, Weiker J, Steiger A, 2005 Nocturnal ghrelin levels-relationship to sleep EEG, the levels of growth hormone, ACTH and cortisol and gender differences. J Sleep Res 14: 329-336.

42. Barkan AL, Dimaraki EV, Jessup SK, Symons KV, Errmolenko M, Jaffe CA, 2003 Ghrelin secretion in humans is sexually dimorphic, suppressed by somatostatin and not affected by the ambient growth hormone levels. J Clin Endocrinol Metab 88: 2180-2184.

43. Uerno H, Yamagushi H, Kangawa K, Nakazato M, 2005 Ghrelin: a gastric peptide that regulates food intake and energy homeostasis. Regul Pept 126: 11-19.

44. Kohno D, Gao HZ, Muroya S, Kikuyama S, Yada T, 2003 Ghrelin directly interacts with neuropeptide-Y-containing neurones in the rat arcuate nucleus: $\mathrm{Ca} 2+$ signalling via protein kinase $\mathrm{A}$ and $\mathrm{N}$-type channel-dependent mechanisms and cross-talk with leptin and orexin. Diabetes 52: 948-956.

45. Tschöp M, Weyer C, Tataranni PA, Devanaryan V, Ravussin E, Heiman ML, 2001 Circulating ghrelin levels are decreased in human obesity. Diabetes 50: 707-709. 
46. Ikezaki A, Hosoda H, Ito K, et al, 2002 Fasting plasma ghrelin levels are negatively correlated with insulin resistance and PAI-1, but not with leptin, in obese children and adolescents. Diabetes 51: 3408-3411.

47. Tolle V, Kadem M, Bluet-Pajot MT, et al, 2003 Balance in ghrelin and leptin plasma levels in anorexia nervosa patients and constitutionally thin women. J Clin Endocrinol Metab 88: 109-116.

48. Weigle DS, Cummings DE, Nweby PD et al, 2003 Roles of leptin and ghrelin in the loss of body weight caused by a low fat, high carbohydrate diet. J Clin Endocrinol Metab 88: 1577-1586.

49. Ueto H, Dube MG, Inui A, Kalra PS, Karla SP, 2004 Leptin modulates orexigenic effects of ghrelin and attenuates adiponectin and insulin levels and selectively the dark-phase feeding as revealed by central leptin gene therapy. Endocrinology 145: 4176-4184.

50. Barazzoni R, Zanetti M, Stebel M, Biolo G, Cattin L, Guarnieri G, 2003 Hyperleptinemia prevents increased plasma ghrelin concentration during short-term moderate caloric restriction in rats. Gastroenterology 124: 11881192.

51. Chan JL, Bullen J, Lee JH, Yiannakouris N, Mantzoros CS, 2004 Ghrelin levels are not regulated by recombinant leptin administration and/or three days of fasting in healthy subjects. J Clin Endocrinol Metab 89: 335-343.

52. Popovic V, Duntas LH, 2005 Brain somatic cross-talk: ghrelin, leptin and ultimate challengers of obesity. Nutr Neurosci 8: 1-5.

53. Radziuck J, 2000 Insulin sensitivity and its measurement: structural commonalities among the methods. J Clin Endocrinol Metab 85: 4426-4433. 